\title{
10 Quantitative and qualitative interviews in older people research
}

\author{
Specificity and usability of the research tool ${ }^{1}$
}

\author{
Piotr Czekanowski
}

\begin{abstract}
What is approximated in this chapter are the qualitative, quantitative and mixed research approaches, which are reflected in three related forms of interview, i.e., qualitative, quantitative and quantitative-qualitative interview (in the latter case in a form proposed by the author of the chapter). The first part of the text presents issues explaining why a large proportion of Polish researchers, especially those less experienced, approach the qualitative methods almost uncritically, underestimating or sometimes even negating the value of research carried out using quantitative techniques. Therefore, the chapter illustrates both the advantages of qualitative (unstructured) interview, such as the possibility of profound insight into the phenomena, as well as its limitations (small number, high impact of the researcher on the achieved results), and an analogous approach was applied to quantitative (structured) interview, where the possibility of testing numerous communities was considered to be an advantage, whereas the effects of the so-called flat empiricism were considered to be a limitation. The conclusion resulting from all the considerations is as follows: it is possible and advisable to go beyond the traditional dichotomy and construct a quantitative-qualitative (mixed) oral interview useful not only in gerontological research, where it finds particularly good application. Such a research technique combines the advantages of qualitative and quantitative interviews, which are usually designed and developed separately, thus allowing minimization of the degree of restrictions relating to them.
\end{abstract}

\section{Introduction}

Choosing the optimal research method ${ }^{2}$ to diagnose how elderly people function, as well as those around them, is not a simple task. This is mainly due to the relatively large number of research approaches and techniques that can be used. Making the right choice by the researcher requires him or her to think deeply and consider many methodological issues to ultimately lead to the selection of the most appropriate solution. During such searches, we may encounter various dilemmas that make this choice difficult. They are often associated with the functioning of certain simplifications and generalizations about which of the research methods are by definition better and which are worse. I would like to analyze this issue on the example of the opposing qualitative and quantitative methods, which, in my opinion, are still juxtaposed as those which have a distinctly different "cognitive ability". I undertake these considerations in order to propose an interview-related solution that can reconcile extreme visions as to what role "qualitative" and "quantitative" methods play in obtaining information from interviewees. Therefore, my considerations in this field can be related to the area of the more and more often presented ideas on the so-called mixed methods (methodologies, 
paradigms) (Creswell, 2013). I would like to add, however, that due to the nature and volume of this text, the solutions presented regarding the division of the two types of the interview proposed in the title of the text are mainly reduced to - using the terminology used by K. Konecki (2000, pp. 20-22) - its technical (neutral) dimension without going too deeply into the paradigmatic issues related to the creation and use of this technique. ${ }^{3}$

\section{Quantitative and qualitative research - end of a dispute?}

I start thinking about the research methods by discussing more general issues. Therefore, they do not refer solely to doing research of the elderly, because so far in the research focused on older adults, we have often used the methods also applied in other sociological or - more broadly - social research.

The issues regarding the division of the research methods into quantitative and qualitative ones have been arousing emotions for many years, constituting - as S. Kvale described it - a hot topic (2004, p. 77). This phenomenon occurs not only in sociology, but also in other sciences. Let the example of W.R. Shadish serve us as an example confirming this observation (1998, p. 3). At the end of the 1990s, this author expressed the certainty that if the members of the American Evaluation Association were to point to one issue, which in the last 20 years had been most often discussed and divided evaluators the most, they would point to quantitative and qualitative disputes. C. Trutkowski, citing the above words, makes the observation that currently the issue of using quantitative and qualitative methods does not entail the emergence of such theoretical divisions among researchers as it did before (2008, p. 127). A similar opinion seems to be shared by other authors, for example M. Halicka, who notes that nowadays the view that qualitative and quantitative research are not in opposition to each other is almost widespread and it is pointless to oppose them $(2004$, p. 62). However, my conviction regarding the dissemination of this view among some Polish scientists is different, although I cannot support it with any results from research in this field. However, reading various reports based on the results of diagnoses made, listening to numerous speeches at symposia, taking part in conference discussions (including the one that became the stimulus to initiate the project within which this book appears), teaching methodology of survey research or conducting talks on the subject of research methods used in social sciences (especially with those less experienced adepts of these sciences) I still notice a tendency to depreciate the so-called quantitative research, especially a structured interview, and glorification of so-called qualitative research, regardless of its type. These people seem to understand what is associated with the term "qualitative research" in a specific way - as noted by U. Flick (2011, p. 22). This specificity is expressed in treating qualitative research as a method that constitutes some new form of research constituting an alternative to - criticized especially in the 1960s and 1970s - quantitative research. This author, however, emphasizes that the research which today is referred to as qualitative has had a long tradition in many disciplines.

It is worth noting that such "oppositional" perception of qualitative and quantitative research is not a new phenomenon in the environment of Polish sociologists, especially those with shorter experience. This issue was raised many years ago by A. Sułek, noting that at the beginning of the 1970s global trends began to reach Poland, calling into question the pre-existing positivist social research paradigm. The author added that after some time the rapid influx of these new trends, such as ethnomethodology or symbolic interactionism, led to a situation in which "they became, especially among the younger generation [my emphasis], obligatory and gained the significance (again!) of 'truly' scientific approaches" (Sułek, 2002, p. 35). 
Perhaps, therefore, the described situations indicating the predominance of qualitative methods over those of a quantitative nature, especially by researchers who are just beginning to try out or practically use the empirical methods of social sciences, are not accidental or coincidental. One may even be inclined to suppose that this situation indicates a certain tendency in this regard. Regardless of whether the observed trend occurs or not in reality, I do notice a one-sided approach to research by some students and scientists, who treat almost all quantitative diagnoses as cursory, shallow and thus of only survey value. It is therefore worth considering what are the potential causes of these types of attitudes. I believe that there are several main reasons conducive directly or indirectly to the emergence of the described situation, which I think include first of all:

\section{Presenting in the mass media: mainly opinion poll results}

Let us point out that in general perception, the survey (probably often identified with each type of an interview) can be associated especially, if not only, with opinion poll organizations diagnosing views of specific persons on a given subject, without going into the motivations conducive to the emergence of such and no other views of these people. ${ }^{4}$ In the described situation, one may even risk the statement that by showing in the mass media mainly only one forms of sociological tools, i.e., that related to public opinion poll, the authors of news and journalistic broadcasts unintentionally lead to the fact that such a narrowed and simplified image of social research is recorded in the minds of the recipients of the media message.

\section{Unfortunate terminology}

Due to the popular associations of this terminology, and as a result quite a narrow and shallow way of understanding the terms "quality" and "quantity", they can also in the case of social research lead to such understanding of the qualitative approach which will be perceived as something high class, i.e., something significant, and the quantitative approach as something massive, cursory, sometimes even primitive.

\section{One-sided presentation of research methods due to specific methodological preferences of lecturers at universities}

This one-sidedness resulting from too far-reaching, and sometimes even ideological, as M. Hammersley calls it, attitudes of the researchers are manifested mainly in that the weaknesses of quantitative methodology are exaggerated and the deficiencies of qualitative analysis are insufficiently outlined. In the event of such a situation, lecturers may promote incomplete knowledge among the participants of their classes about the advantages and limitations of both qualitative and quantitative research approaches (Hammersley, 1992, p. 163; Silverman, 2012, p. 64).

\section{A clear advantage of the number of currently published publications devoted to qualitative research over those describing quantitative research}

In recent years, a very large number of methodology books have appeared on the Polish publishing market, including many based on translations, but presenting mainly the issues of qualitative research. On the one hand, this large number of publications describing 
qualitative methods is a most advantageous phenomenon: on the other hand, however which can be considered a paradox - such a significant number of them can even give the impression among some readers that the whole world of scholars is currently primarily interested in qualitative research, because those of a quantitative nature are less useful and therefore are in retreat.

\section{Insufficient degree of research curiosity as well as independence and inquisitiveness in searching for reliable knowledge}

One of the effects of this - let's call it - scientific immaturity is the existence in some academic environments of a kind of "fashion" for using qualitative methods in research. The inexperienced - in the broad sense of the word - researchers often think that these methods are relatively simple to use, and the issues of reliability and accuracy of measurement are of secondary importance. With this approach, every study is basically successful, because it does bring some results, which without an embarrassing restriction of even elementary standardization, can always "somehow" be interpreted. Therefore, we probably still come across supporters of Barney Glaser's approach cited below (1998, p. 254), whose recommendation was quoted by U. Flick in his work, assuming, however, that this stage in the development of qualitative research, in which researchers fully trusted their methods, is already over: "Trust grounded theory, it works fine, just do it and publish the results" (2011, p. 22).

Listing the main reasons that may be conducive to the occurrence of excessive simplifications in the understanding of the relationship between "quality" and "quantity" in relation to ongoing research, I ask myself whether it is possible to limit the force of their impact so that the image of quantitative research could become more reliable in the near future. I think that achieving this goal is somehow real, but probably only in the long term, and the activities associated with it are certainly not easy to implement. For example, it is difficult to change the established attitudes of researchers in the near future, enrich information programs with in-depth sociological analyses or encourage more young people to critically study methodological issues. Nevertheless, it is worth starting to look for solutions among those which are probably the simplest, i.e., the ones related to the language we use overall, not only with our academic contacts. Perhaps, for example, a departure from the use of the term "quantitative research" or the popularization of terms that in turn would replace the term "qualitative research", such as the hermeneutic, reconstructive or interpretative approach, which is cited by U. Flick $(2012, \text { p. } 23)^{5}$ or - which also comes to my mind - simply descriptive, it would change the described situation, thus limiting the perception of qualitative and quantitative methods in unjustified opposition.

\section{Dilemmas encountered when choosing the right research approach}

Once you are aware that quantitative and qualitative research should not be contrasted with each other, can you also clearly indicate which of these research approaches is better in specific types of research, including, in particular, gerontological research? I believe that it is impossible to give a generalized answer to such a question without specifying the particular purpose and object of the diagnosis we make, because each of the approaches used has its own individual advantages and specific limitations. I share in this respect the observation of B. Synak that, just as there is no single, valid theory of ageing, there is also no single, good research method. However, wanting to make it easier for the researcher to 
make the right choice, let's think about what potential restrictions we may encounter using both the so-called qualitative and quantitative methods (Synak, 1997, p. 20).

I begin a brief analysis of these issues with B. Synak's other thoughts. On the one hand, for many years he insisted that qualitative methods be used in Polish research on the elderly (1988, p. 30, 1997, p. 20); on the other hand, however, he indicated, referring also to other authors, numerous and significant features that may have a positive or negative impact on the implementation and development of the results from such research (1997, pp. 17-19). There is no doubt that proponents of qualitative methods used in various studies must take these issues into account, because of, for example:

- consequences of the possibility of freely creating an image of the studied phenomenon based on its subjective, sometimes selective, stereotypical or even biased perception (the reliability of the researcher);

- difficulties conditioned by the level of the ability to ask open-ended questions (the need to focus on the experience of the surveyed people) and the ability to create a favorable atmosphere to be able to respond freely;

- narrowing the scope of research, i.e., the size of the surveyed community or meeting places, to the number in which the researcher is able to participate;

- complications occurring during the presentation of the research results to diverse recipients related to convincing them that the diagnosis reflects the existing reality.

B. Synak's conclusion resulting from his more detailed analysis of the pros and limitations occurring in qualitative research presented in his cited article is as follows: "All in all, it should be said that qualitative research is more difficult than the empirical, quantitative approach; it requires better researcher preparation, greater responsibility, sensitivity and empathy. In gerontological research, the difficulties are even greater" (1997, p. 19). In my opinion, this thesis, which is probably worth in-depth discussion, should not lead to an over-simplistic conclusion that in such a case quantitative research is easy to implement and does not require appropriate methodical, substantive and ethical preparation, unless we mean - signaled by the aforementioned author in an earlier part of his argument (1997, p. 15) - flat empiricism. What is meant by it? In my opinion, this term may mean at least four situations, namely:

- creating research "from behind the desk", i.e., without sufficient knowledge of the researched issues, field conditions or the peculiarities of the subjects, with the exception of piloting (trial tests);

- lowering the level of necessary standardization, sometimes found in the work of multidisciplinary teams, which is the result of misunderstanding by some representatives of, for example, medical sciences, the need to clearly formulate questions and then posing them to interviewees in a unified way, which is required in structured interviews used in social sciences;

- the researcher's use in the interview only of closed-ended questions, if this is not substantively justified, and is motivated solely by the intention of easily and quickly obtaining information from the survey;

- developing research results in a way described by D. Caplowitz as crass empiricism, which is expressed in the fact that the researcher analyzes all data (counts all possible dependencies) before he thinks over and prepares a detailed table of contents on the basis of which he will create a research report (Caplowitz 1983, pp. 383-386). ${ }^{6}$ 
The examples presented above illustrating the occurrence of potentially numerous methodological difficulties that we may encounter when preparing and implementing both qualitative and quantitative research probably allow us to better understand why making decisions as to which of these research approaches will suit our competences and needs is not easy. Probably it was the occurrence of the dilemmas among researchers connected with the need to make the choice between either the qualitative or quantitative method, as well as the desire to limit the scope of the mentioned methodological difficulties, that contributed to the fact that nowadays we are increasingly encountering tendencies to combine quantitative and qualitative optics into a certain whole. ${ }^{7} \mathrm{M}$. Halicka, for example, deals with the issue in detail (2004, pp. 62-69; see also Flick, 2011, pp. 153-177; Creswell, 2013). The search for further ideas in this area, one of which I present below, is therefore a good opportunity to go beyond the traditional dichotomy in order to work out - as stated by U. Flick using the thoughts of A. Tashakkori and C. Teddli - "a methodological third way" (Flick, 2012, p. 33; Tashakkori and Teddlie, 2003, p. IX).

\section{Quantitative-qualitative interview and its characteristics ${ }^{8}$}

I think that a very useful tool for a structured face-to-face interview is a well-prepared questionnaire. I am referring to the interview, which, generally speaking, combines the features of the so-called qualitative and quantitative interview because:

1 through the appropriate type and structure of the questions asked (and observations made) it allows us to investigate the phenomenon we are interested in as deeply as possible, which can be considered a qualitative element of the diagnosis made by means of this interview;

2 by examining a large number of members of a given community, it enables the creation of its overall image or gives the opportunity to compare the situation occurring between communities, groups or their representatives, which is a quantitative dimension of such a diagnosis.

Let's take a closer look at both of the indicated features of a quantitative-qualitative interview, thinking about whether and how one can combine the qualities of qualitative and quantitative interviews in one research technique, i.e., interviews usually perceived separately. ${ }^{9}$ Bringing these issues closer, I want to emphasize that in the above sentence (as well as in other places in this chapter) I consciously use the terms such as "so-called" or "conventional" to make it clear that in my understanding of the content under the terms "quality" and "quantity" I treat them as two elements co-creating a specific and complementary whole. The justification for this approach can be found, for example, in the longer argument presented by J. Sztumski, who concludes by saying that there is no subject of empirical research that would be defined only in a qualitative or only in a quantitative manner (2010, p. 257). In my opinion, E. Babbie also approaches the issues related to the quality-quantity relation stating that

each observation is qualitative at the beginning, regardless of whether it is experiencing someone's intelligence or placing the clue on a measurement scale, or the answer marked in the questionnaire. The nature of any of these things is not numerical or quantitative, but sometimes it is useful to give them this numerical form. 


\section{Qualitative dimension}

When it comes to the first of the distinguished features of the interview, i.e., the one related to the questions used to obtain information and expand knowledge, then the type of the interview is carefully matched both with open-ended questions, which are usually the heart of the unstructured or in-depth interview, i.e., those forms of interviews that are recognized as qualitative interviews, and with semi-open and closed-ended questions, associated mainly with standardized, ${ }^{10}$ and therefore quantitative interviews. Of course, we will notice that combining (mixing) three types of questions in one questionnaire is not in itself anything new, but what is important in this case is - which seems obvious - a comprehensive concept of the research undertaken with a clearly defined goal that we intend to achieve through the coexistence of different types of questions, and this goal is - let us repeat - to investigate the issue that interests us as fully as possible. Therefore, despite the fact that in a combined quantitative and qualitative interview we usually do not use only open-ended questions, as is the case in the abovementioned unstructured interviews, the researcher using this type of interview largely sets the same goals as $\mathrm{S}$. Kvale indicates in relation to a qualitative interview, stating that "a qualitative research interview tries to understand the world from the perspective of the interviewees, comprehend the meaning of human experience, discover the world of their life prior to scientific explanations" (2012, p. 19). In the interview form that I propose, in order to explore the depth of this more subjective, internal world of the interviewees, there appear open-ended, semi-open and closed-ended questions mixed up in various proportions, which often complement each other, thus encouraging the search for relevant content and additionally fulfilling the function of control questions. ${ }^{11}$ In order to learn objectively about the feelings of the interviewees occurring "prior to" scientific diagnosis and not to lose the opportunity to find out what the respondents would really like to say themselves, the varied research tool proposed is not adopting certain preliminary assumptions or creating operational definitions based on the results of previously conducted research or as described in the literature on the subject. Therefore, in cases where we make certain assumptions in advance, the interview is not intended to impose on the interviewees the vision of the researcher, but to find out to what extent the researcher's concept, which was in no way even signaled to the interviewees, is reflected in their feelings.

In the combined quantitative-qualitative interview - as has already been indicated above - we treat observation as an element that complements its "qualitative" dimension, i.e., the one related to obtaining information important for the researcher. As in the case of other standardized oral interviews, we do not treat such observation as an independent research method, because it plays only a supplementary role in them. Although in quantitative research, as pointed out by D. Silverman (2012, pp. 39-40), observation is usually not considered an important method of data collection, because it is difficult to conduct observational study on some samples, in relation to the quantitative-qualitative interview, it can be assigned at least two important tasks:

- First, such observation is helpful in properly reading the verbal message addressed to us. In order to understand properly - as S. Gertsmann notes - what our interviewee is saying to us, the interviewer observes his behavior and interprets it immediately (Gertsmann, 1985, p. 182). The subject of observation - as the author writes further is always a certain whole, which consists of both the statements of the examined person and his facial expression, pantomime or sound of the voice. To the benefits of 
the overall observation of the examined person, I include, for example, the opportunity to perceive the interlocutor's manifestations of his mood expressed during the interview, in the form of, for example, exasperation or amusement, which in turn can affect the nature of the answers given.

- Second, observation accompanying the interview enables obtaining additional information about the interviewee and his or her surroundings. By conducting the interview in a specific place, often at the interviewee's place, we have the opportunity to examine people in a certain way in their natural location, gaining some opportunity for the correct interpretation of the recognized phenomena, because they are embedded in a specific context. However, it is worth repeating over and over again that during an interview what we should assume is the perspective of the person being interviewed, and not our own, because the assessment of the observed reality from the perspective of the researcher may not coincide at all with the feelings of the examined person.

Focusing on the complementary role of observation in an interview, I would like to point out that the interviewer has the opportunity to save his or her observations in a place properly prepared in the questionnaire form called "Interviewer's Comments", based on the points - which is crucial - prepared in advance by the researcher. The questions addressed to the interviewer relate to such issues as the degree of understanding of individual questions by the interviewee, the interviewee's apparent attitude toward the interviewer or the presence of third parties during the interview. This is a fairly precise list of issues to which every interviewer is to draw attention during observations, which later allows preparation of, among others, some collective summaries. Therefore, these numerical sets of results from the observation carried out can be considered as another element that reflects the combination of qualitative and quantitative components in the interview, and for this reason I propose to treat it in this text as a kind of transition to presenting the "quantitative" dimensions of this interview. I will only add that, in my opinion, the role of these supplementary entries made by interviewers is often underestimated by researchers and may prove to be very important or even crucial, especially when it is necessary to make an auxiliary interpretation of the answers given or to assess their credibility.

\section{Quantitative dimension}

When it comes to the second of the features of the qualitative-quantitative interview listed at the beginning of the third section, i.e., the one that allows the examination of numerous representatives of the communities we are interested in, I do not see any contradiction in the fact that the so-called "qualitative" research intentions presented above, i.e., the ones that enable investigation of the complex social reality, could not be carried out by conducting this kind of interview with a large number of people. ${ }^{12} \mathrm{I}$ am convinced that this would facilitate the achievement of the goals referred to by U. Flick regarding qualitative methods: "All approaches seek regularity in meanings ... allowing the researcher to formulate - more or less generalized - models, typology and theory as ways of describing and explaining social or psychological issues" (2012, p. 13). We should note that to a large extent J. Lutyński wanted to achieve similar goals by means of a questionnaire interview, though not by means of a qualitative interview, recognizing that it serves "to learn both about the behaviour and mental experiences, including opinions, as well as phenomena that very often constitute complex and diverse sets of both, such as human attitudes, norms of conduct, habits, etc.” (1994, p. 152). E. Babbie sees 
these issues similarly, noting that surveys can be used for various purposes, i.e., descriptive, explanatory and exploratory (2007, p. 268).

When discussing the most important issues related to the so-called quantitative dimension of the research conducted on the basis of the quantitative-qualitative interview, it should be emphasized that in order to conduct such interviews (as well as other standardized oral interviews) we usually need carefully prepared interviewers. This situation is understandable because rarely is a researcher able to reach larger groups of interviewees alone. However, in the case of gerontological research there are two key and complementary, which I emphasize, requirements for interviewers. First, it would be desirable to have such interviewers who are proficient in the implementation of questionnaire interviews. This is a feature that probably is common for many of them, although it is worth remembering what, for example, S. Kvale draws attention to, that we learn interviewing skills mainly through practice (2012, p. 20). However, the second extremely important feature that characterizes the interviewers, which must go hand in hand with the first, is having reliable knowledge in the field of gerontology. ${ }^{13}$ The specificity of research on advanced age people implies such combined requirements. What is this specificity? For example, there is a need to free yourself from the quite common stereotypical perception of older people in society, ${ }^{14}$ or to be sensitive to the moral rules of the so-called previous era, complex health issues and extremely important ethical issues.

Just indicting how I imagine the model person conducting an interview with an older man (or on issues related to old age) I am aware that finding reliable interviewers with "dual" qualifications, i.e., equipped with methodological skills and gerontological knowledge, is not an easy task. For many years, what we have paid attention to and what we have been admonishing (Czekanowski, 1993, pp. 4-5, 6, 87), is the fact that unfortunately in Poland there has been no nationwide research center to date that would be specialized in, among others, conducting widely understood analyses and gerontological research, and which, in addition, would have at its disposal a network of interviewers optimally prepared for such research. In the current situation, it is mainly the duty and responsibility of the researchers who "equip" with the interviewers whose services we intend to use, at least with the most relevant knowledge related to ageing and old age or at least with the subject related to the research (this can be done by preparing supporting materials for them or indicating literature or relevant training). However, it is worth being aware that we do not always have the opportunity to prepare our own network of interviewers or even appropriate training in the field of gerontology of those interviewers that we will have at our disposal. In many cases, therefore, the authors of gerontological scientific projects commission interviews to various survey laboratories, which probably very rarely (if at all) have employees properly qualified to perform such tasks (in such situations, we try to establish substantive cooperation with them, although probably only exceptionally the opportunity arises). Needless to say, the occurrence of shortcomings in the interviewer's work is always highly inadvisable because - as we know - it is primarily the interviewers' professionalism that determines the degree of reliability of the research material collected during their contact with the interviewees.

Concluding the presentation of the general characteristics of the quantitative-qualitative interview as an attempt to combine the advantages of both the quantitative and qualitative interview, I will recall another observation by U. Flick (2012, p. 22). According to this author, the progressive development of qualitative research methods meant that the term "qualitative research" is treated more and more precisely because it has ceased to be "defined by negation - qualitative research is non-quantitative, non-standardized, etc. - but through a set of features specific for them". I think that using this line of reasoning, it can 
also be assumed that a structured interview is no longer just a non-qualitative interview, and therefore it can also be useful in in-depth recognition of the phenomena that are of interest to us. I assume that this departure from the extreme dichotomy already mentioned will lead to a situation in which we will increasingly improve also the interviews of the most universal nature possible, i.e., the ones that will combine conventional quantitative and qualitative features, previously perceived differently.

\section{Conclusion}

To sum up the considerations in this chapter, I would like to answer potential questions about why, in my opinion, the quantitative-qualitative interview is worth disseminating (and further improving), and why I propose its use in the research of older people.

Referring briefly to the first question, I think, which I have tried to prove by presenting numerous arguments, that such an interview combines the advantages often attributed only to qualitative interviews with those that distinguish a quantitative interview. Thanks to such integration, it is a complex research tool open in its intention, but closed in the form of a questionnaire, useful for detailed understanding of the broadly understood life situation of the interviewed. This type of an interview allows you to create a picture of larger communities and make comparisons that interest you. In addition, in the presence of the previously described polarization of positions regarding quantity and quality in social research, constructing one type of a relatively universal interview, i.e., containing both qualitative conventional features and meeting the so-called quantitative requirements, may nonetheless be the easiest solution to implement. I think that this relative simplicity will appear in the case of some researchers appearing to be more willing to understand each other and, as a result, to seek further ideas useful in diagnosing the functioning of individual members of our societies. However, I realize that this task is not easy to achieve and entails the need to decide on some, and not only methodological, compromises. In turn, when it comes to the answer to the second question, related to the usefulness of a quantitative-qualitative interview to diagnose the situation of elderly people, then we note that in surveys on older people we rarely have the opportunity to occupy them for longer periods of time (or reappear to use further research methods). This happens for a variety of reasons, even as a result of the progressive effects of various diseases limiting or even preventing further contact with such interviewees, or because of a lack of finance for a continuation of a survey. In the discussed situations, the proposed type of interview may be at least a substitute for the application of a classic recommendation to use as many research techniques as possible in a specific diagnosis, because thanks to this we gain the opportunity of multidirectional, and thus more complete recognition of the phenomena that interest us.

\section{Notes}

1 This text develops and revises ideas included in the chapter entitled Quantitative and Qualitative Approach: An Attempt to Go beyond the Traditional Dichotomy, from the book Social Aspects of the Ageing Population in Poland: A Perspective of the Sociology of Old Age (Czekanowski, 2012).

2 The terms: method, technique and research tool are used interchangeably in this chapter.

3 K. Konecki (2000), however, emphasizes that when applying the paradigmatic criterion, such a contradiction between qualitative and quantitative techniques may occur.

4 This perception of a standardized interview is part of J.-C. Kaufmann's thoughts, who writes that this kind of an interview "reaches only one layer: superficial opinions that are directly available", and thus can only be used - as he calls it - for surface analysis (2010, p. 29). 
5 I would also like to add that analyzing terminological issues, U. Flick notes that in relation to qualitative research, one can sometimes come across terms such as "inquiry" instead of the commonly used "research" or even a situation where we do not use any of these terms, using instead the name "ethnography" for this type of research approach (2012, p. 23).

6 Probably J.-C. Kaufmann meant something similar writing about the need to combat "abstract empiricism" in relation to the production of raw data and methodological formalism (2010, p. 21).

7 S. Kvale draws attention to the fact that attempts to build bridges between qualitative and quantitative methods have not been very successful, and the conclusion of the debate or qualitativequantitative dispute seems premature. According to this author, the research in social sciences is still dominated by a dual quantitative and qualitative concept, with the presence of quantitative sphere hegemony, though (Kvale, 2004, pp. 75-78).

8 Other names that I propose for this form of interview is an integrated, multidimensional, holistic, combined or mixed interview, although it is difficult to predict if any of these names could be popularized. The last of these terms, i.e., a mixed interview, is not the slickest term in Polish, among others because of its meaning, although it can be associated most easily with the so-called mixed methods.

9 Such a dichotomous understanding of both types of interviews is presented, for example, by D. Silverman. The author indicates that in the case of qualitative research, the interview is based on open-ended questions and is carried out on small samples. According to Silverman, "the important issue is 'authenticity' rather than reliability [of research]". On the other hand, in the case of quantitative research, the interview serves survey purposes; it contains mainly closedended questions and is carried out on randomly selected samples from the whole population. According to Silverman, "the central methodological issue for quantitative researchers is the reliability of the interview scenario and the representativeness of the sample" (2012, pp. 39-40).

10 In Polish, the interview has various names, such as standardized, categorized, structured or questionnaire interview.

11 This complementary, and at the same time checking, function of closed-ended and open-ended questions worked very well in recognizing in elderly people such personal and subtle feelings as loneliness. In examining this phenomenon, a dozen or so closed-ended questions from the shortened version of the UCLA Loneliness Scale with those taken from the NUY Loneliness Scale, as well as open-ended questions concerning the causes leading to loneliness, experiences related to its feeling and ways of dealing with loneliness were used (Czekanowski, 1993).

12 According to E. Babbie "surveys are probably the best method available for those researchers who want to collect original data to describe a population too large to be observed directly" (2007, p. 268).

13 I confirmed my belief in the importance, or even necessity, of implementing the appropriate postulate, i.e., methodological and gerontological preparation of interviewers, after detailed familiarization with 1000 very extensive, 200-question interviews, which made up the Polish part of the European research carried out under the international EUROFAMCARE project dedicated to family carers of older people in Europe. As it turned out, these were the interviewers who were practicing nurses or social workers (i.e., those equipped with professional knowledge about the functioning of older people) who with greater understanding and, as a result, more accurately wrote down the answers to questions about, for example, the level of fitness, than, for example, graduates or $\mathrm{PhD}$ students of sociology, familiar especially with the general principles of doing research. In the cases discussed, therefore, we were dealing with a certain influence of interviewers on the results of the survey.

14 These stereotypes may concern not only interviewers but even researchers themselves. The confirmation of this observation can be found in the experience of Z. Woźniak from research on the oldest citizens from Poznań, who wrote:

The strength of internalized stereotypes on old age in the early stages of socialisation may be testified by students of the Social Work Studies who persistently maintain opinions, full of anxiety and reserve, on the behavior and functioning of older people during the preparatory work for the research, - even though they previously had classes in geriatrics and gerontology. Only direct contact seriously violated their stereotypical image of older age and the life of an older man. 


\section{References}

Babbie, E. (2007). The practice of social research, trans. a team of translators. Warsaw: PWN Scientific Publishing House.

Caplowitz, D. (1983). The stages of social research. New York, Chichester, Brisbane, Toronto and Singapore: John Wiley \& Sons.

Creswell, J.W. (2013). Research design: qualitative, quantitative and mixed methods approaches, trans. J. Gilewicz. 3rd ed. Kraków: Jagiellonian University Press.

Czekanowski, P. (1993). Loneliness of older people and the factors that differentiate it (unpublished doctoral thesis). University of Silesia, Katowice.

Czekanowski, P. (2012). Social aspects of the ageing population in Poland: a perspective of the sociology of old age. Gdańsk: University of Gdańsk Publishing House.

Czekanowski, P. (2018). Dilemmas in researching family carers of elderly people: a sociologist's view of old age and carer's perspective. Social Pedagogy, 3(69), 81-90.

Flick, U. (2011). Managing quality in qualitative research, trans. P. Tomanek. Warsaw: PWN Scientific Publishing House.

Flick, U. (2012). Designing qualitative research, trans. P. Tomanek. Warsaw: PWN Scientific Publishing House.

Glaser, B.G. (1998). Doing grounded theory: issues and discussions. Mill Valley, CA: Sociology Press.

Gertsmann, S. (1985). Conversation and interview in psychology. Warsaw: PWN.

Halicka, M. (2004). Life satisfaction of the elderly: a theoretical-empirical study. Białystok: Medical University of Białystok.

Hammersley, M. (1992). What's wrong with ethnography: methodological explorations. London: Routledge.

Kaufmann, J-C. (2010). The comprehensive interview, trans. A. Kapciak. Warsaw: Academic Publishing House.

Konecki, K. (2000). Study of methodology of qualitative research: grounded theory. Warsaw: PWN Scientific Publishing House.

Kvale, S. (2004). InterViews: an introduction to qualitative research interviewing, trans. S. Zabielski. Białystok: Trans Humana University Publishing House.

Kvale, S. (2012). Doing interviews, trans. A. Dziuban. Warsaw: PWN Scientific Publishing House.

Lutyński, J. (1994). Research methods in social sciences: selected problems. Łódź: Łódź Scientific Society.

Shadish, W.R. (1998). Evaluation theory is who we are. American Journal of Evaluation, 1, 1-19.

Silverman, D. (2012). Interpreting qualitative data: methods of analysing talk, text and interaction, trans. M. Głowacka-Grajper and J. Ostrowska. 2nd ed. Warsaw: PWN Scientific Publishing House.

Sułek, A. (2002). A garden of sociological methodology. Warsaw: SCHOLAR.

Synak, B. (1988). Research directions and the state of social gerontology in Poland. In: B. Synak and T. Wróblewski (eds), Gerontology advances. Warsaw: PZWL.

Synak, B. (1997). Qualitative research in sociology of old age: possibilities and dilemmas. Polish Gerontology, 4, 14-21.

Sztumski, J. (2010). An introduction to methods and techniques of social research. 7th ed., amended and updated. Katowice: "Silesia" Scientific Publishing House.

Tashakkori, A. and Teddlie, C. (2003). Major issues and controversies in the use of mixed methods in social and behavioral research. In: A. Tashakkori and C. Teddlie (eds), Handbook of mixed methods in social and behavioral research. Thousand Oaks, CA: Sage.

Trutkowski, C. (2008). On conditions of using qualitative methods in social and evaluation research. In: A. Haber and M. Szałas (eds), Environment and methodology of evaluation. Warsaw: Polish Agency for Enterprise Development.

Woźniak, Z. (1997). The oldest of Poznań seniors: the autumn of life in a gerontological perspective. Poznań: City Publisher. 